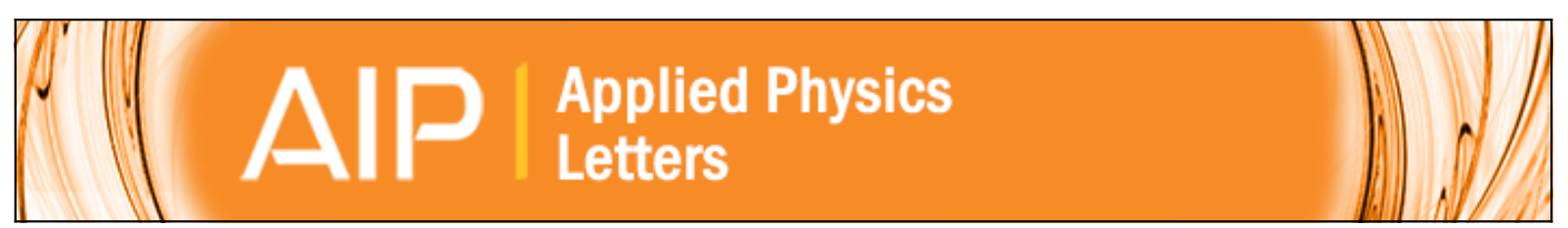

\title{
Field-effect BaTiO3-Si solar cells
}

Wentao Wang, Fude Liu, Chor Man Lau, Lei Wang, Guandong Yang, Dawei Zheng, and Zhigang Li

Citation: Applied Physics Letters 104, 123901 (2014); doi: 10.1063/1.4869556

View online: http://dx.doi.org/10.1063/1.4869556

View Table of Contents: http://scitation.aip.org/content/aip/journal/apl/104/12?ver=pdfcov

Published by the AIP Publishing

\section{Articles you may be interested in}

Transport mechanisms and effective Schottky barrier height of $\mathrm{ZnO} / \mathrm{a}-\mathrm{Si}: \mathrm{H}$ and $\mathrm{ZnO} / \mu \mathrm{c}-\mathrm{Si}: \mathrm{H}$ heterojunction solar cells

J. Appl. Phys. 114, 184505 (2013); 10.1063/1.4831661

Modeling the effect of Si $\mathrm{O} 2$ additions and cooling rate on the electrical behavior of donor-acceptor codoped positive temperature coefficient thermistors

J. Appl. Phys. 103, 123713 (2008); 10.1063/1.2937245

Method to extract diffusion length from solar cell parameters-Application to polycrystalline silicon

J. Appl. Phys. 93, 5447 (2003); 10.1063/1.1565676

Effect of Al-induced gettering and back surface field on the efficiency of Si solar cells

J. Appl. Phys. 90, 5388 (2001); 10.1063/1.1412575

Impurity photovoltaic effect in indium-doped silicon solar cells

J. Appl. Phys. 89, 4030 (2001); 10.1063/1.1354651

High-Voltage Amplifiers

- Voltage Range from $\pm 50 \mathrm{~V}$ to $\pm 60 \mathrm{kV}$

- Current to 25A

Electrostatic Voltmeters

- Contacting \& Non-contacting

- Sensitive to $1 \mathrm{mV}$

- Measure to $20 \mathrm{kV}$
ENABLING RESEARCH AND

INNOVATION IN DIELECTRICS,

ELECTROSTATICS, MATERIALS, PLASMAS AND PIEZOS

TRek www.trekinc.com 


\title{
Field-effect $\mathrm{BaTiO}_{3}$-Si solar cells
}

\author{
Wentao Wang, ${ }^{1}$ Fude Liu, ${ }^{1, a)}$ Chor Man Lau, ${ }^{1}$ Lei Wang, ${ }^{1}$ Guandong Yang, ${ }^{1}$ Dawei Zheng, ${ }^{1}$ \\ and Zhigang $\mathrm{Li}^{2}$ \\ ${ }^{1}$ Department of Mechanical Engineering, The University of Hong Kong, Pokfulam Road, Hong Kong, China \\ ${ }^{2}$ Department of Mechanical and Aerospace Engineering, The Hong Kong University of Science and Technology, \\ Hong Kong, China
}

(Received 9 February 2014; accepted 9 March 2014; published online 25 March 2014)

\begin{abstract}
Conventional solar cells make use of the spatial variation in electronic environment due to junctions for charge separation. We investigated field-effect $\mathrm{BaTiO}_{3}-\mathrm{Si}$ solar cells that utilize the bound surface charges of $\mathrm{BaTiO}_{3}$ to separate charge carriers in silicon. Rectifying behavior and photovoltaic effect were observed on cells with forward polarization. Theoretical simulation indicated that the induced electric field due to $\mathrm{BaTiO}_{3}$ polarization could extend into the silicon layer, which is consistent with experimental observations. In addition, adjusting relevant parameters may optimize the electric field distribution. The cells are promising in terms of material selection, device design, and fabrication. (C) 2014 AIP Publishing LLC. [http://dx.doi.org/10.1063/1.4869556]
\end{abstract}

Photovoltaic devices are generally developed for optimizing three key steps for charge carriers: generation, separation, and transport. Conventional solar cells make use of the spatial variation in electronic environment due to junctions for charge separation, and the $\mathrm{PN}$ junction structure is a classic model of this concept. However, this kind of structure has limitations on materials selection and device fabrication to form a workable junction due to issues such as lattice mismatch, doping, and band alignment. Moreover, either homojunctions or hetero-junctions inevitably introduce defect states that act as recombination or trapping centers for charge carriers. ${ }^{1}$ In contrast, ferroelectric-based photovoltaic cells, which usually consist of a ferroelectric layer sandwiched between two electrode plates, can avoid aforementioned issues and, thus, have attracted considerable attention recently. ${ }^{2}$ These cells have an internal electric field throughout the bulk region originating from electrical polarizations that are not completely compensated by screening charges. ${ }^{3}$ Consequently, a fascinating charge separation mechanism exists in these cells, and even the light-induced open circuit voltage $\left(\mathrm{V}_{\mathrm{oc}}\right)$ can be greater than the band gap. ${ }^{4}$ However, ferroelectric materials are, in general, highly insulating because of their large band gaps, ${ }^{5}$ which limits the absorption of sunlight. Thus, ferroelectrics should be coupled with semiconductors in order to achieve photovoltaic cells with good performance.

In this work, we investigated a type of solar cells that combine a ferroelectric $\left(\mathrm{BaTiO}_{3}\right)$ and a semiconductor $(\mathrm{Si})$. The cells avoid the PN junction structure and utilize the bound surface charges of $\mathrm{BaTiO}_{3}$ to separate photongenerated charge carriers in $\mathrm{Si}$. This structure has an interesting feature that free charge carriers and fixed charge carriers are physically separated from each other. Thus, it is promising in preparing solar cells because of its more flexibility in material selection, device design, and fabrication.

The schematic of device structure and a real cell are shown in Fig. 1, respectively. As illustrated in Fig. 1(a), the

\footnotetext{
${ }^{\text {a) }}$ Author to whom correspondence should be addressed. Electronic mail: fordliu@hku.hk.
}

cell consists of a ferroelectric layer, a semiconductor layer, a pair of poling electrodes ( $P$-electrodes), and a pair of working electrodes (anode and cathode). The $P$-electrodes patterns are aligned well with those of anode and cathode, respectively. Anode and cathode collect electrons and holes, respectively, which are photon generated in the semiconductor layer, under the influence of the external field due to ferroelectric polarizations; electrons then flow through the external circuit to do work on the load (R) and finally recombine with holes at the cathode. Note that neighboring regions in the ferroelectric layer are polarized in opposite directions such that negative and positive bound surface charges are accumulated to different electrodes in a fashion as shown in the figure. To fabricate a real cell (Fig. 1(b)), silicon and $\mathrm{BaTiO}_{3}$ were chosen as the semiconductor absorber and ferroelectric layer, respectively, because of mature technologies. A piece of $p$-type single crystalline $\mathrm{Si}$ wafer with thickness of $280 \mu \mathrm{m}$ and size of $20 \times 20 \mathrm{~mm}^{2}$ was cleaned with the RCA (= Radio Corporation of America) clean. Due to their different work functions, $\mathrm{Ti}$ and $\mathrm{Au}$ were chosen for anode and cathode, respectively, that were deposited on Si with sputtering using a shadow mask. $\mathrm{BaTiO}_{3}$ was then spin coated on $\mathrm{Si}$ with the sol-gel method using a precursor solution $(0.40 \mathrm{~mol} / \mathrm{l})$ based on $\mathrm{Ba}\left(\mathrm{CH}_{3} \mathrm{COO}\right)_{2}, \mathrm{Ti}\left(\mathrm{OC}_{2} \mathrm{H}_{5}\right)_{4}$, polyvinylpyrrolidone (PVP)-360000, $\mathrm{H}_{2} \mathrm{O}, \mathrm{CH}_{3} \mathrm{COOH}$, and $\mathrm{C}_{2} \mathrm{H}_{5} \mathrm{OH}$. ${ }^{6}$ After each spin coating step, the sample was dried at $350{ }^{\circ} \mathrm{C}$ for $10 \mathrm{~min}$ before proceeding to next step; the coating may be repeated several times depending on the film thickness required. Then, the sample was stepwise heated at $300^{\circ} \mathrm{C}$ and $500^{\circ} \mathrm{C}$ for $10 \mathrm{~min}$, respectively, and finally at $700^{\circ} \mathrm{C}$ for $15 \mathrm{~min}$ to achieve full crystallization of $\mathrm{BaTiO}_{3} .{ }^{7}$ P-electrodes of $\mathrm{Ag}$ were deposited on $\mathrm{BaTiO}_{3}$ with thermal evaporation. Post annealing at $450{ }^{\circ} \mathrm{C}$ for $15 \mathrm{~min}$ was then conducted to form good metal contacts. Finally, the sample was wired out with Ag paste and metal wire, and then covered with epoxy and glass for insulating. The poling was conducted at $180^{\circ} \mathrm{C}$ and then at room temperature for $10 \mathrm{~min}$, respectively. During the poling process, the silver $P$-electrodes were grounded, and $18 \mathrm{~V}$ was applied on the Au cathode and $-18 \mathrm{~V}$ on the Ti anode simultaneously, which is defined as forward polarization 


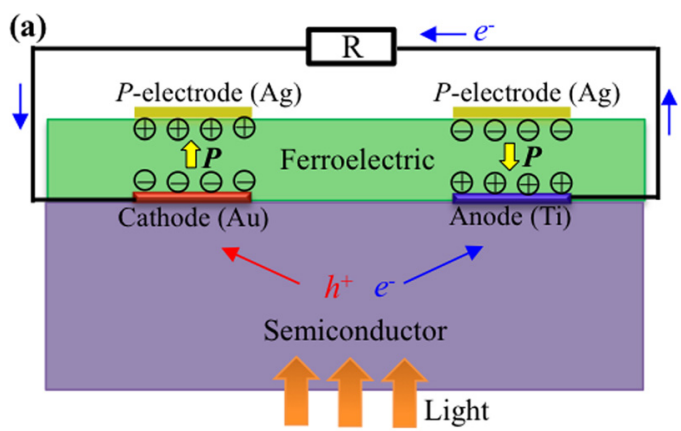

(b)

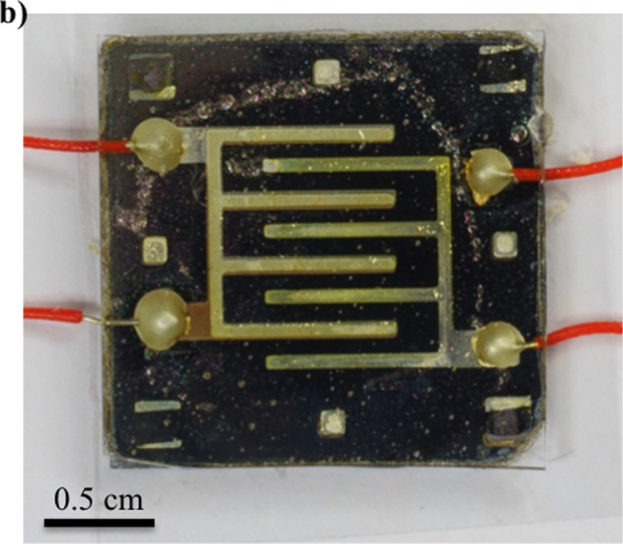

FIG. 1. Schematic of device structure and real cell. (a) Schematic of device structure (cross-section view; not drown to scale) and (b) real cell (top-down view from the ferroelectric side).

(see Fig. 1(a)); it is called reverse polarization when the external poling voltage are swapped between anode and cathode. The electrical characterization was carried out with a standard solar simulator (ABET Sun 2000 coupled with Keithley 2602A). All current-voltage (I-V) measurements were conducted by sweeping the voltage from negative to positive. The distribution of the induced electric field in $\mathrm{Si}$ due to the bound surface charges of $\mathrm{BaTiO}_{3}$ was simulated with the finiteelement method using the AC/DC Module of COMSOL ${ }^{\circledR}$.

The way of poling on the ferroelectric plays an important role in device performance. Fig. 2 depicts the I-V curves of the before-polarization and reverse-polarization states, respectively, under dark condition. Before polarization, the $\mathrm{I}-\mathrm{V}$ curve is a straight line with high resistivity. After reverse polarization, the I-V curve in general is still linear but with lower resistivity. So the cell shows Ohmic behavior for both cases. However, after forward polarization, the conduction behavior under dark condition is changed dramatically; a substantial diode rectifying behavior is evident in the corresponding I-V curve (black one in Fig. 3(a)). The rectification ratio is $\sim 220$ at $\mathrm{V}= \pm 0.5 \mathrm{~V}$. The diode-like behavior has been constantly observed in all our cells ( $>20$ cells). Therefore, the polarization of $\mathrm{BaTiO}_{3}$ can greatly affect the transport of charge carriers in $\mathrm{Si}$.

Under sunlight illumination at $100 \mathrm{~mW} / \mathrm{cm}^{2}$, the $\mathrm{I}-\mathrm{V}$ curve shifts downward for the forward-polarization state, exhibiting the photovoltaic effect (brown curve in Fig. 3(a)). The corresponding $\mathrm{V}_{\mathrm{oc}}$ and $\mathrm{I}_{\mathrm{sc}}$ are $\sim 170 \mathrm{mV}$ and $0.035 \mu \mathrm{A}$, respectively. We also studied the time-dependent $\mathrm{I}_{\mathrm{sc}}$ when the illumination was switched on or off under short-circuit condition (Fig. 3(b)). We see that the photocurrent is generated whenever the cell is exposed to sunlight, and it

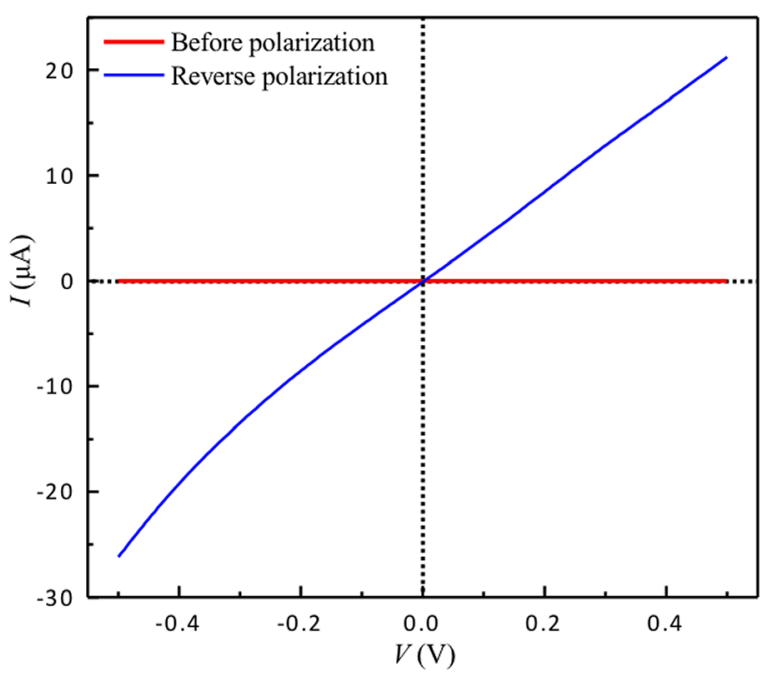

FIG. 2. I-V curves of the before-polarization and reverse-polarization states, respectively, under dark condition.

disappears whenever the illumination is off. Therefore, photon-generated charge carriers in Si can be separated and then collected by anode or cathode. Because the band gap of $\mathrm{BaTiO}_{3}$ is $3.2 \mathrm{eV}$ and the light is shot from the thick Si side, it is reasonable to assume that photon-generated charge carriers in Si mainly contribute to the photovoltaic effect. In addition, there are no initial small spikes of photocurrent, which rule out the pyroelectric effect as well. ${ }^{8}$
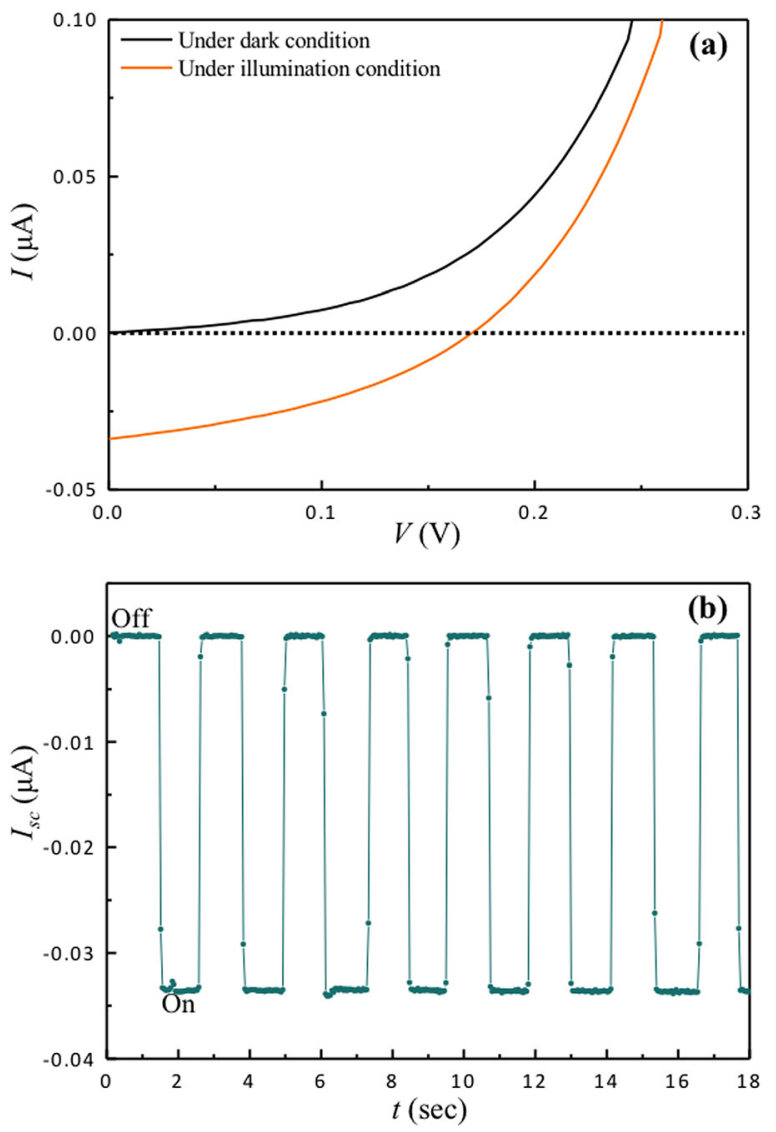

FIG. 3. Rectifying behavior and photovoltaic effect of the forward-polarization state. (a) I-V curves under dark and illumination conditions, respectively. (b) Time-dependent $\mathrm{I}_{\mathrm{sc}}$ when the illumination is switched on or off. 


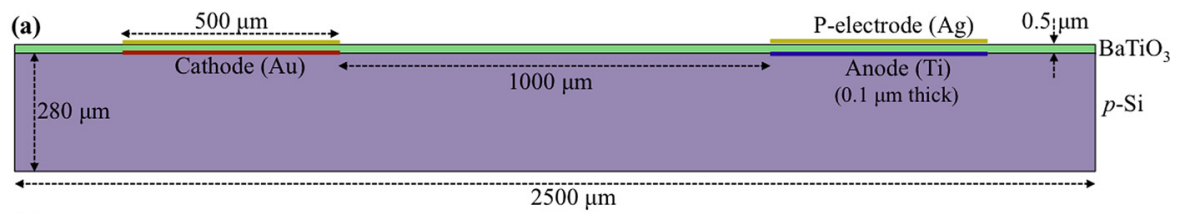

(b)

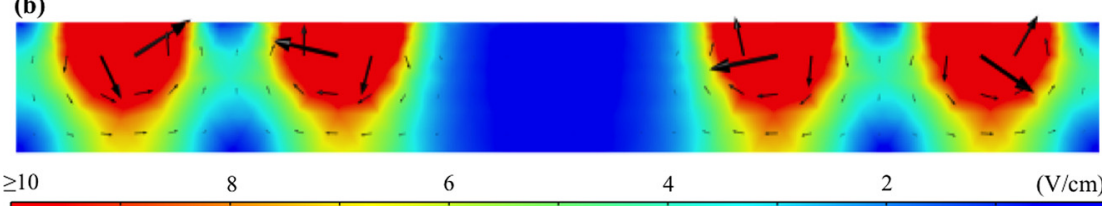

FIG. 4. Simulation of the electric field distribution. (a) Model geometry (not drown to scale). (b) Simulated electric field distribution in the real cell. Also included is the electric field legend that is color-coded.
We now understand the crucial role played by the forward polarization in the rectifying behavior and photovoltaic effect. To further understand this, it is necessary to know the distribution of the induced electric field in $\mathrm{Si}$ due to the bound surface charges of $\mathrm{BaTiO}_{3}$. Fig. 4(a) represents the simulation model whose geometry parameters are from real cells. The relative permittivity of $\mathrm{Si}, \mathrm{BaTiO}_{3}$, and $\mathrm{Au}$ is $11.9,{ }^{9} 290,{ }^{10}$ and $6.9,{ }^{11}$ respectively. The relative permittivity of $\mathrm{Ti}$ and $\mathrm{Ag}$ is unknown in the literature; we simply took the same value of 6.9 for them too (which is not expected to greatly affect the over picture on electric field distribution). Next, the bound surface charge density was set to be $\pm 0.10 \mathrm{C} / \mathrm{m}^{2}$ (typical value) for the polarized $\mathrm{BaTiO}_{3}$ layer. The simulated electric field distribution in the cell is shown in Fig. 4(b). Also included is the electric field legend that is color-coded for easy viewing. Because the $\mathrm{BaTiO}_{3}$ layer is very thin compared to the $\mathrm{Si}$ layer, it is barely seen in the figure. It is obvious that the induced electric field extends into the Si layer. Overall, the electric field points toward the cathode and points away from the anode, as indicated by black arrows. Thus photon-generated electrons and holes would drift to the anode and cathode, respectively, under the influence of the induced electric field. The current flow direction is then consistent with our experimental results shown in Fig. 3. Note that the electric field is in the order of $10^{\circ} \mathrm{V} / \mathrm{cm}$, which is much weaker than that of a typical PN junction (in the order of $\left.10^{3}-10^{4} \mathrm{~V} / \mathrm{cm}\right) .{ }^{12}$ In addition, the electric field distribution in the Si layer is not uniform. In particular, the field is relatively stronger in regions (in red) near the electrodes and is relatively weaker in regions (in blue) between cathode and anode. The weak and non-uniform electric field may be one major reason for the poor device performance.

The device performance may be improved through geometry optimization. Fig. 5 shows the simulation of the electric field distribution in a possible optimized cell after
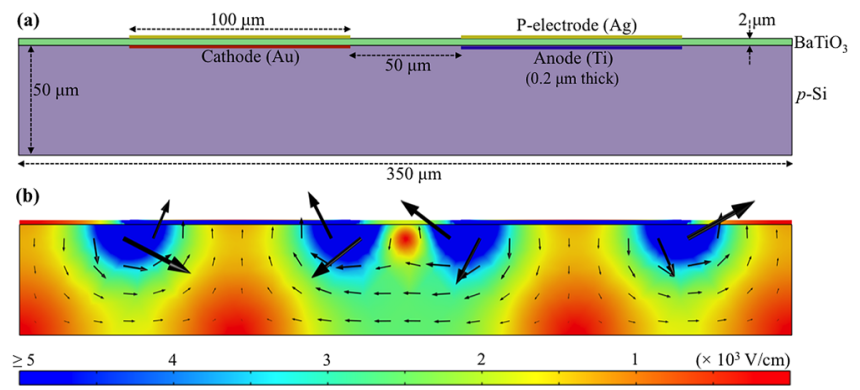

FIG. 5. Simulation of the electric field distribution in a possible optimized cell. (a) Model geometry (not drown to scale). (b) Electric field distribution in the optimized cell. Also included is the electric field legend that is color-coded. adjusting the dimension parameters. We see that in the optimized cell, the electric field in $\mathrm{Si}$ is now increased to be in the order of $10^{3} \mathrm{~V} / \mathrm{cm}$, which is comparable to that in a typical PN junction. In addition, its electric field distribution is more uniform. It is then expected that real cells based on the optimized model may have better performance.

It should be pointed out that in our simulation, we have not considered the screening effect of metal electrodes on the bound surface charges of the ferroelectric, which may weaken the induced electric field in the semiconductor. ${ }^{13}$ Transparent conducting oxides (TCO) with less carrier density and longer screening length may be used as electrodes instead to mitigate this problem. In real cells, besides the weak and non-uniform electric field, poor metal contacts with high resistance are another major reason for the poor device performance, in particular, low current, as indicated in Figs. 2 and 3. In addition, we may need to consider other issues such as surface passivation, ionic defects in the ferroelectric, ${ }^{14}$ and possible carrier injection between $\mathrm{BaTiO}_{3}$ and $\mathrm{Si}$. All the aforementioned issues are good points to address in the future work. In this study, however, we focus mainly on the concept demonstration of $\mathrm{BaTiO}_{3}$-Si cells.

In summary, we investigated field-effect $\mathrm{BaTiO}_{3}$-Si solar cells in detail with both experimental results and theoretical simulation. Real solar cells showed the rectifying behavior and photovoltaic effect after forward polarization only. Theoretical simulation indicated that the induced electric field due to the $\mathrm{BaTiO}_{3}$ polarization could extend into the Si layer and then photon-generated carries in Si could be separated and collected for electricity generation. Adjusting relevant parameters such as dimension, materials, and polarization charge density may optimize the electric field distribution for improving device performance. Although we have focused only on $\mathrm{BaTiO}_{3}$ and $\mathrm{Si}$, the concept introduced herein may be applied to other material systems because of its flexibility in material selection, device design, and fabrication.

The authors acknowledge the financial support of the Seed Funding Programme for Basic Research at HKU (Project Code 201211159091), the HKU Initiative on Clean Energy \& Environment (HKU-ICEE), and the University Development Fund (UDF) 2009-2010 (Second Round).

${ }^{1}$ J. Nelson, The Physics of Solar Cells (Imperial College Press, 2003), p. 17-39.

${ }^{2}$ W. Ji, K. Yao, and Y. C. Liang, Adv. Mater. 22, 1763 (2010); D. W. Cao, H. Zhang, L. Fang, W. Dong, F. G. Zheng, and M. R. Shen, Mater. Chem. Phys. 129, 783 (2011); J. Xu, D. W. Cao, L. Fang, F. G. Zheng, M. R. Shen, and X. L. Wu, J. Appl. Phys. 106, 113705 (2009). 
${ }^{3}$ M. Qin, K. Yao, and Y. C. Liang, Appl. Phys. Lett. 93, 122904 (2008).

${ }^{4}$ S. Y. Yang, J. Seidel, S. J. Byrnes, P. Shafer, C. H. Yang, M. D. Rossell, P. Yu, Y. H. Chu, J. F. Scott, J. W. Ager, L. W. Martin, and R. Ramesh, Nat. Nanotechnol. 5, 143 (2010); K. Yao, B. K. Gan, M. M. Chen, and S. Shannigrahi, Appl. Phys. Lett. 87, 212906 (2005).

${ }^{5}$ M. Dawber, K. M. Rabe, and J. F. Scott, Rev. Mod. Phys. 77, 1083 (2005).

${ }^{6}$ H. Kozuka, S. Takenaka, H. Tokita, and M. Okubayashi, J. Eur. Ceram. Soc. 24, 1585 (2004).

${ }^{7}$ H. Kozuka and M. Kajimura, J. Am. Ceram. Soc. 83, 1056 (2000).

${ }^{8}$ T. Choi, S. Lee, Y. J. Choi, V. Kiryukhin, and S.-W. Cheong, Science 324, 63 (2009).
${ }^{9}$ M. Tabib-Azar, N. S. Shoemaker, and S. Harris, Meas. Sci. Technol. 4, 583 (1993).

${ }^{10}$ H. Kozuka and A. Higuchi, J. Am. Ceram. Soc. 86, 33 (2003).

${ }^{11}$ I. N. Shklyarevskii and P. L. Pakhmov, Opt. Spektrosk. 34, 163 (1973).

${ }^{12}$ B. Streetman and S. Banerjee, Solid State Electronic Devices (Prentice Hall, 2000), p. 167-169.

${ }^{13}$ M. Qin, K. Yao, and Y. C. Liang, Appl. Phys. Lett. 95(2), 022912 (2009); W. Regan, S. Byrnes, W. Gannett, O. Ergen, O. Vazquez-Mena, F. Wang, and A. Zettl, Nano Lett. 12, 4300 (2012).

${ }^{14}$ H. T. Yi, T. Choi, S. G. Choi, Y. S. Oh, and S. W. Cheong, Adv. Mater. 23, 3403 (2011). 